\title{
Crack Detection of Fan Blade Based on Natural Frequencies
}

\author{
Mengyao Yu $\mathbb{D}^{1},{ }^{1}$ Sheng Fu, ${ }^{1}$ Yinbo Gao, ${ }^{1}$ Hao Zheng, ${ }^{2}$ and Yonggang Xu ${ }^{3}$ \\ ${ }^{1}$ Beijing Precision Metrology Laboratory, Beijing University of Technology, Beijing 100124, China \\ ${ }^{2}$ Ennovation System Control Co., Ltd., Beijing 101111, China \\ ${ }^{3}$ Beijing Key Laboratory of Advanced Manufacturing Technology, Beijing University of Technology, Beijing 100022, China
}

Correspondence should be addressed to Mengyao Yu; yumengyao@emails.bjut.edu.cn

Received 1 September 2017; Accepted 8 January 2018; Published 5 February 2018

Academic Editor: Jingyin Li

Copyright (C) 2018 Mengyao Yu et al. This is an open access article distributed under the Creative Commons Attribution License, which permits unrestricted use, distribution, and reproduction in any medium, provided the original work is properly cited.

\begin{abstract}
A simple method was developed to detect damage based on a discrete mathematical model for fan blades using changes in natural frequencies combined with a fluid-structure analysis. In addition, a numerical approach was developed for the fluid-structure analysis. The results of numerical simulation provided the natural frequency data for each mode under different locations and sizes of a single crack in a blade. A fault database was built using Matlab. The damage of a blade was detected using the changes in natural frequencies. This study will assist in investigating the effect of a crack on a structure from different perspectives; the simulation results show the effectiveness of this approach.
\end{abstract}

\section{Introduction}

Crack failures continually occur in fan blades, which cause interruption of operation and increase costs, decrease product quality, and affect the safety of operators [1-3]. Fault detection for blades of rotating machinery at earlier stage can prevent it from breaking down and reduce maintenance time. Therefore, efficient and reliable fault diagnosis method is essential to predict the existence and state of the damage before the occurrence of crack failure.

Significant efforts have been invested for developing different fault detection and diagnosis techniques for crack identification in rotating machinery. Existing fault diagnosis methods are roughly divided into two categories: methods based on expert system and variation of vibration characteristics.

Artificial intelligence (AI) techniques, such as fuzzy logic, genetic algorithms (GA) and artificial neural network (ANN), are utilized to detect fault as well. Several authors used AI techniques based on vibration characteristics for fault detection and diagnosis of various structures [4-6]. Oberholster and Heyns [4] used ANN for monitoring the online condition of axial-flow fan blades; the fault features extracted from 24 kinds of different damage levels of the crack blade are used to train the neural network. They showed that the vibration signals obtained from two sensors can effectively diagnose the extent of the crack development. Genetic algorithms appear as a desirable approach to optimize an objective function that depends on crack position and size [7-10]. Mehrjoo et al. [11] used the GAs to search the solution of an inverse problem where the cracks' location and size are calculated. It is shown that this method is able to identify various crack configurations in a cracked beam. Combination of two or more intelligent techniques $[12,13]$ allows one to overcome the limitations of individual techniques and achieve better performance by utilizing capabilities of each individual classifier. The authors in [14] proposed a genetic fuzzy system for online damage detection using changes in vibration measurements between damaged and intact conditions. It has been shown that the combination of genetic algorithms with fuzzy inference systems possesses enormous advantages. Another integration of multi-intelligent techniques has also been carried out in recent years [15].

Intelligent identification method requires a lot of training samples for accuracy, but the crack damage of large axial fan blades is not easy to be fabricated, which brings about the problem of insufficient fault samples. Besides, the selection criteria of the best training algorithm of the fastest rate of convergence for some of the "black box" techniques 
have not been addressed appropriately, which resulted in an uncertainty on the training speed optimization related to the type and quantity of the training sample.

Another category of existing methods includes those based on examination of changes in natural frequencies, mode shapes, or mode shape curvatures [16-18]. Wang et al. [18] used mode shape difference curvature to detect the crack location based on FEM and aerodynamic loads' calculation. Their method has been proved efficiently through the experiment on a wind turbine blade and simulation on a multilayer composite material blade. But the curvature of mode shape of the damaged blade is too tiny $\left(10^{-4}\right)$ to be detected. These methods are generally based on the inspection of mode shape changes and need measurements with high accuracies. They require expensive data acquisition and monitoring systems with the properties such as multiple sensors, high sensitivity, large hard disc capacity, and fast processing. Changes in the natural frequencies are used more often than deviation of mode shapes, since frequencies can be measured more easily than mode shapes, and they are less seriously affected by experimental error.

During the last few decades, intense research on the detection of crack using the changes in frequency has been carried out by researchers [19-22]. They noted that any localized damage would affect each mode differently as the existence of the crack in a structure causes a change in its stiffness. Consequently, there would also be a change in the dynamic response of the structure, and then the change in frequencies related to crack location and size has been used to evaluate the state of crack through an inverse processing. The authors in [22] used soft spring to simulate the boundary conditions of a cantilever beam with a single crack. Yang et al. [23] detected the crack of a beam based on an energy numerical model which had been regarded as a continuous model with varying moment of inertia. Most of the current approaches take the cracked structure as a continuous model which makes it hard to achieve the exact solution with complex boundary conditions.

The aim of this study is to investigate the influence of natural frequency of cracked fan blades based on different theoretical analysis taking the structure as a discrete model for monitoring blade conditions and predicting the existence and severity of the crack in the blade. Besides, fan blades are subjected to centrifugal, air bending, and vibratory loads $[24,25]$. This repeated loading and unloading influences the dynamic response of the blades due to the high-speed rotation. Therefore, the cracked blade in this study will be simulated in a rotate state and subjected to the pressure caused by the air flow in order to make the simulation results more reliable.

In the present paper, a novel damage detection method based on a discrete mathematical model for fan blades is proposed. This technique uses the FEM based dynamics analysis to detect the single crack and identify its location and size, which can readily obtain the fault sample database. In this study, a finite element model of $621 \mathrm{~mm}$ length fan blade has been built using shell elements with structural steel, aerodynamic loads are calculated to make the simulation results more reliable, and then dynamics analysis is performed. By using the changes in natural frequencies, the damage in blades can be detected efficiently and precisely.

\section{Methodology}

This approach makes use of synthetic data and consists of three steps: data generation, establishment of the fault sample database, and fault detection. At the first stage, vibration characteristics of the intact and damaged fan blades are analyzed by combining fan blade model with fluid flow model to generate the data sets of natural frequency. In the second step, Matlab is applied to build the fault sample database. In the final step, the changes in natural frequencies of damaged blade are used to identify location and size of a single crack in a blade.

2.1. Data Generation. The vibration data can be generated from numerical analysis of the whole mine fan in this procedure. A series of numerical simulations have been carried out to obtain the data sets of natural frequency, which can be used to identify various damage states in the fan blades. For each run of the simulation, different locations and sizes of a single crack are considered.

2.1.1. Structural Modelling. To investigate the influence of cracks on the dynamic behavior in fan blades, dynamic analysis is concerned in terms of modelling the cracked blades, researching the vibration characteristics, establishing the effective fault features for condition monitoring of the rotor system, and detecting cracks state in an early stage. Several crack modelling approaches are analyzed including the stress energy release rate (SERR) method and the finite element method (FEM). In this paper, a 3D model of the axialflow fan AGF606-2.82-1.58-2 has been designed in ANSYS Workbench using FEM method according to the dimensions of the fan at Datong coal mine (see Figure 1(a)). To simplify the structure of the axial-flow fan, only several principal parts of the mine fan have been considered in the 3D model. A complete 3D model of the mine fan is shown in Figure 1(b); the fan model consists of 109,121 tetrahedral elements and 168,310 nodes.

The axial-flow fan consists of the impeller, the collector, the diffuser, and the air duct (see Figures 1(c)-1(g)). The two impellers are connected with bearing and shaft. The same way of connection is used between the impeller and the air duct.

The boundary conditions of the fan model are shown in Figure 2. The impeller is rigidly connected to the main shaft of the rotor and zero displacement is assumed at the baseplate. The pressure distributions obtained from CFD simulations are used on the remaining surfaces.

2.1.2. Fluid Flow Modelling. The CFD simulation of all flow channels of the fan rotor has been performed to obtain pressure distributions on the plate blade. The entire fluid passageway between the inlet from the collector side and the outlet from the diffuser side of the mine fan is considered as shown in Figure 3. The extension of the inlet and outlet was added to avoid any effect it would have had on the flow near the blades. The CFD simulation is also performed in ANSYS Workbench which can readily achieve pressures of the remaining blade. The whole computational mesh consists of 329,799 tetrahedral elements and 63,509 nodes (Figure 3(a)). 


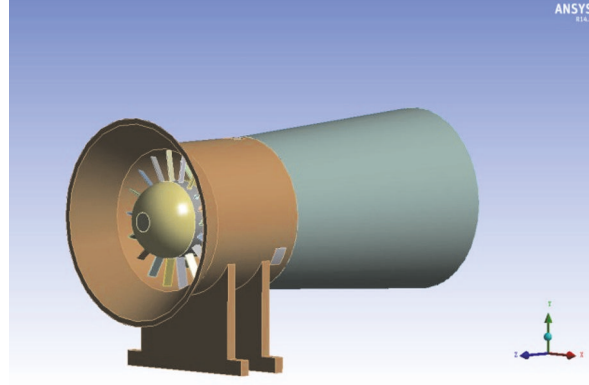

(a) Geometrical model of axial-flow fan

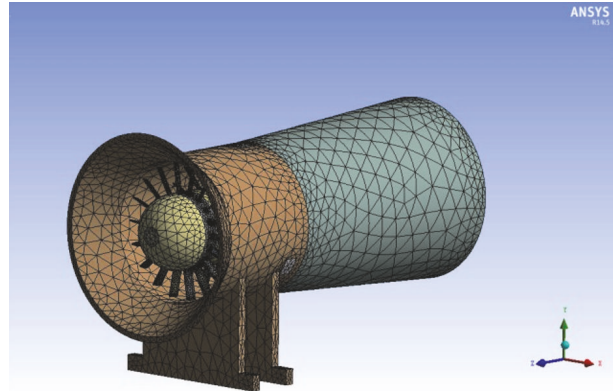

(b) 3D unstructured grids of the computational domain

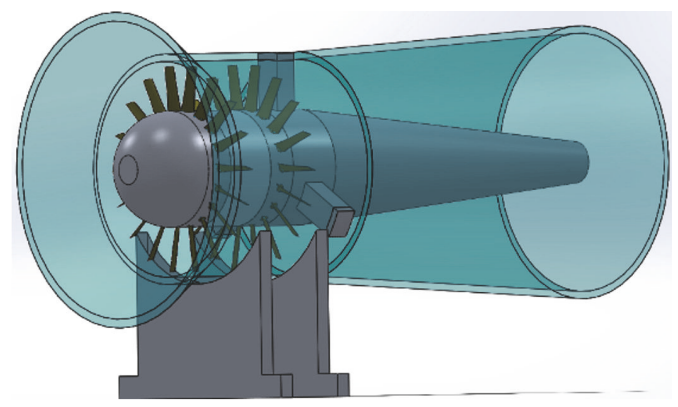

(c) Perspective view

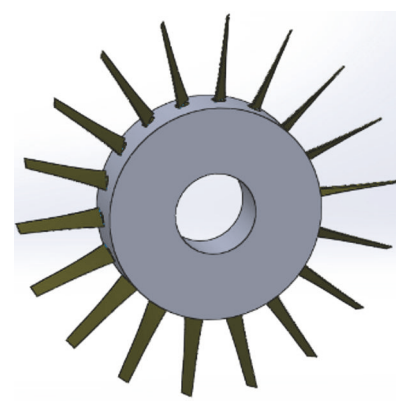

(d) The impeller

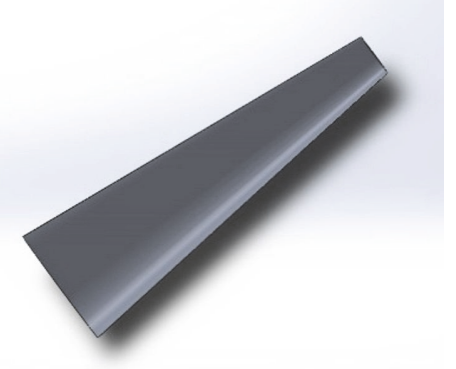

(e) The air duct

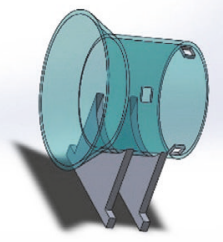

(f) The collector

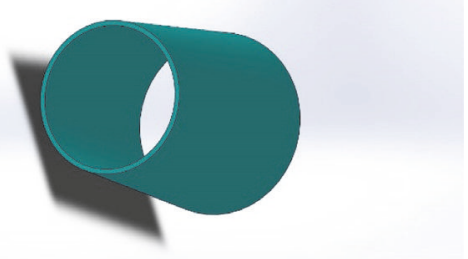

(g) The diffuser

Figure 1

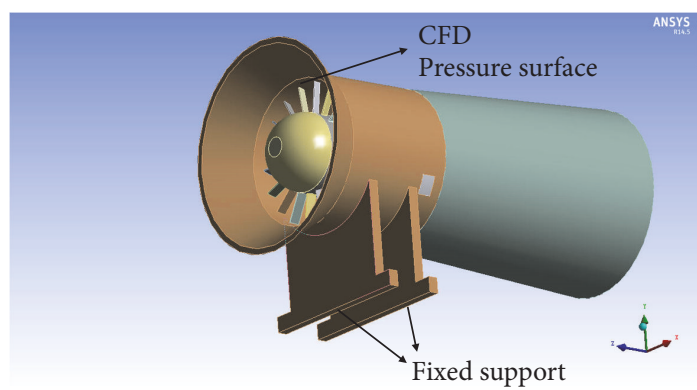

(a)

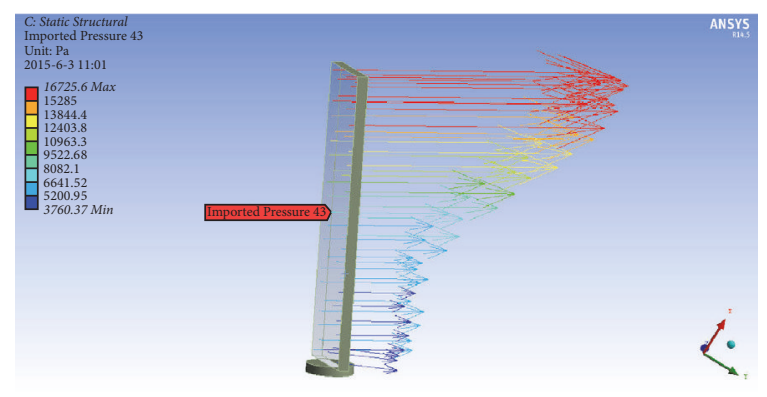

(b)

FIGURE 2: (a) Boundary conditions for the structural modelling and (b) closer look of the pressure surface.

The computations assume steady state incompressible uniform fluid flow in circumferential direction of the axialflow fan rotor. In order to make the simulation more reliable, the entire fluid passageway has been divided into two domains (see Figure 3(b)): the static domain and the rotation air domain. In the static domain, the airflow moves only along the axial direction while the rotation air domain has a rotational velocity. Constant outlet boundary conditions are defined by an opening with an average relative pressure equal to atmospheric pressure.

2.1.3. Fluid-Structure Coupled Analysis. The vibration characteristics of the axial-flow mine fan are examined by coupling fluid-structure models in order to obtain the natural 


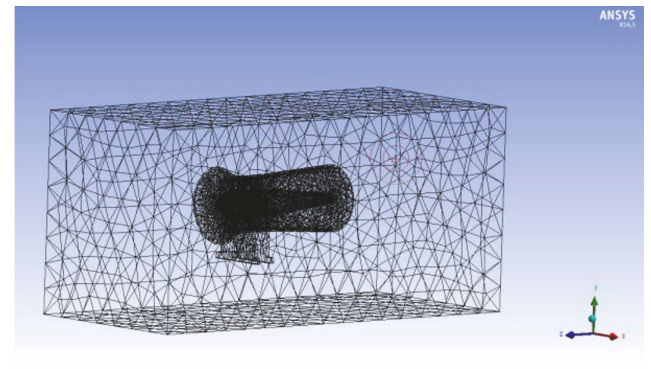

(a)

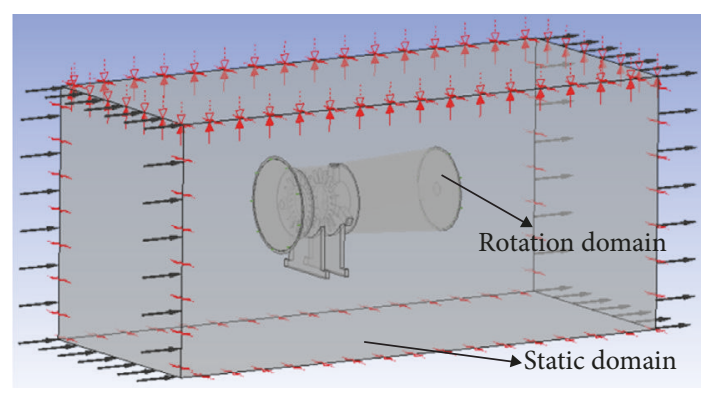

(b)

FIgURE 3: (a) Finite element mesh of the fan and (b) boundary conditions for the fluid flow modelling.

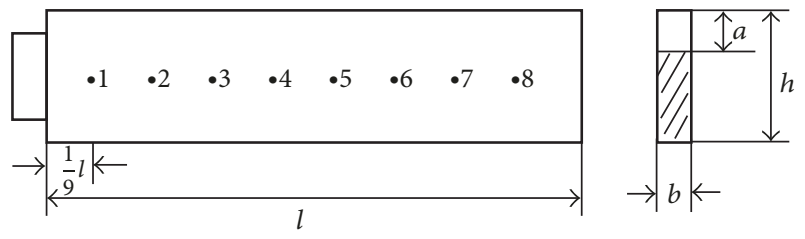

Figure 4: Plate blade with a single rectilinear crack.

frequencies of the intact and damaged blade with different crack conditions. It is assumed that a single rectilinear crack is located in one of the plate blades of the impeller. Each plate blade is made of structural steel of cross-sectional area $180 \mathrm{~mm} \times 23 \mathrm{~mm}$ with a length of $621 \mathrm{~mm}$. Figure 4 demonstrates the settings of crack in the blade. Cracks were initiated at eight different locations from blade root to blade tip (along the length of the blade) ranging from $\beta=1 / 9 l$ to $\beta=8 / 9 l$ ( $\beta$ is the crack location and $l$ is the blade length) in steps of $1 / 9 l$. For each location, three crack sizes, $\alpha=$ $1 / 3 h, \alpha=1 / 2 h$, and $\alpha=2 / 3 h$ ( $\alpha$ is the crack size and $h$ is the blade width), have been considered. Through the fluidstructure couple analysis, the first three natural frequencies of the blade can be readily achieved and the data will become more reliable compared with the modal analysis without CFD simulation.

2.2. Fault Database. The first three natural frequencies of the cracked fan blade obtained from the simulations in ANSYS Workbench are a function of crack location and crack size. In order to detect the crack state, Matlab is applied to build the fault database. Specifically, $x$-axis represents the crack location, $y$-axis represents the crack size, and $z$-axis represents the natural frequency of the blade. Through using the cubic interpolation to curve fitting at each point, a threedimensional plot of the first three natural frequencies of plate blade can be readily achieved.

2.3. Dynamics Analysis. Defects existing in a structure cause a change in its stiffness, and consequently this could also affect its dynamic characteristic. In order to find out the dynamic characteristic, modal analysis should be carried out for the structure.

2.3.1. Basic Equation. Modal analysis can determine the vibration characteristics (natural frequencies and mode shapes) of the blade structure. Plate blade belongs to the cantilever; the chief form of its distortion is the bending deformation while the blade vibrating direction is perpendicular to the axis direction. An infinitesimal segment $d x$ which was intercepted from the blade length $l$ has been analyzed according to the motion equation and the basic theories of the mechanics of materials. And the blade bending free vibration equation is as follows:

$$
\rho A \frac{\partial^{2} y}{\partial t^{2}}+E I \frac{\partial^{4} y}{\partial x^{4}}=0
$$

where $y(x, t)$ is the lateral displacement of the blade, where $x$ represents the location of the section and $t$ represents the time, $\rho$ is the density of the blade, $A$ is the cross-sectional area of the blade, and $E I$ is the bending stiffness.

It is assumed that the solution of the vibration equation of the blade is $y(x, t)=Y(x) \varphi(t), \varphi(t)=A \sin \omega t+B \cos \omega t$, where $A$ and $B$ are constants determined by the initial conditions.

According to the cantilever boundary conditions

$$
\begin{aligned}
Y & =0, \\
\frac{d Y}{d x} & =0, \\
\frac{d^{2} Y}{d x^{2}} & =0, \\
\frac{d^{3} Y}{d x^{3}} & =0,
\end{aligned}
$$

the $n$th natural frequency $\left(\omega_{n}\right)$ of the blade can be obtained from equations as follows:

$$
\omega_{n}=\beta_{n}^{2} \sqrt{\frac{E I}{\rho A}},
$$

where $\beta_{n} l$ is the characteristic root of the blade bending free vibration equation and $\beta_{1} l=1.875, \beta_{2} l=4.694, \beta_{3} l=$ 7.855 .

2.3.2. Damage Blade Modal Analysis. When there is a crack in the blade, the boundary conditions of the blade become very complex. It is difficult to work out exact solutions of natural frequency while regarding the blade as a continuous model. 


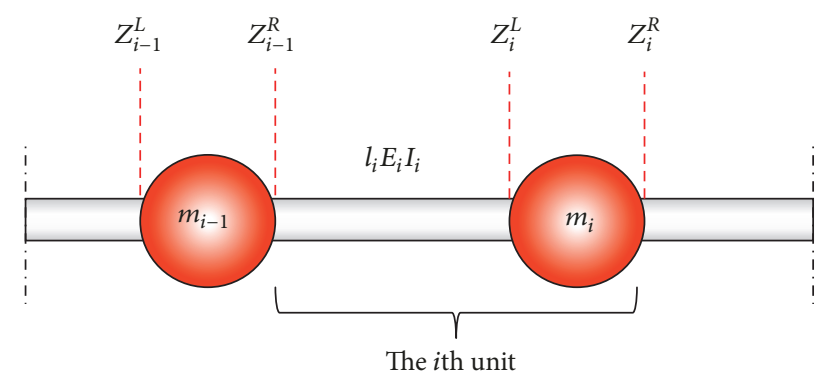

FIgURE 5: Mathematical model of the $i$ th unit.

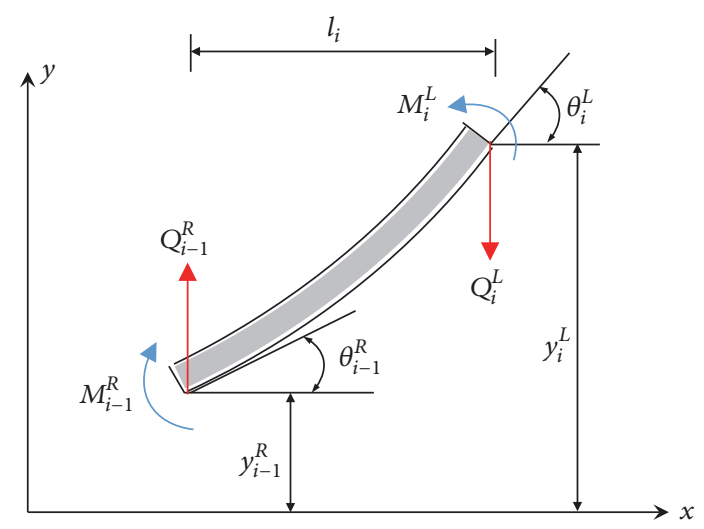

FIGURE 6: Stress analysis figure of the $i$ th massless beam segment.

In this paper, a discretization method has been proposed to work out the natural frequency of the blade.

Specifically, the entire blade structure being regarded as a cantilever was discretized by a number of quality units as shown in Figure 5. Each unit includes a massless beam segment and a centralized quality. Taking into account when there is a crack in the blade, the angle of rotation around the crack will change evidently. In order to study the influence of crack on the whole blade, each unit has four state variables which consists of $Z=\left(\begin{array}{llll}y & \theta & M & Q\end{array}\right)^{T}$, where $y$ is the deflection, $\theta$ is the angle of rotation, $M$ is the bending moment, and $Q$ is the shear force of the section of the centralized quality.

It is assumed that the crack exists in the $i$ th centralized quality. Firstly, stress analysis of the $i$ th massless beam segment has been performed as shown in Figure 6.

It is supposed that $M_{i}(x), \theta_{i}(x)$, and $y_{i}(x)$ are the bending moment, angle of rotation, and deflection of the section, respectively, being $x \mathrm{~mm}$ away from the last centralized quality $((i-1)$ th $)$ in the $i$ th massless beam segment.

According to the basic theories of the mechanics of materials, $M_{i}(x), \theta_{i}(x)$, and $y_{i}(x)$ are expressed as follows:

$$
\begin{aligned}
& M_{i}(x)=M_{i-1}^{R}+Q_{i-1}^{R} x \\
& \theta_{i}(x)=\theta_{i-1}^{R}+\frac{1}{E_{i} I_{i}} \int_{0}^{x} M_{i}(x) d x \\
& y_{i}(x)=y_{i-1}^{R}+\int_{0}^{x} \theta_{i}(x) d x .
\end{aligned}
$$

The equilibrium condition of the $i$ th massless beam segment can be written as follows:

$$
\begin{aligned}
Q_{i}^{L} & =Q_{i-1}^{R} \\
M_{i}^{L} & =M_{i-1}^{R}+Q_{i-1}^{R} l_{i} .
\end{aligned}
$$

And then the transfer matrix between the left side of the $i$ th centralized quality and the right side of the $(i-1)$ th centralized quality can be given by

$$
\left[\begin{array}{c}
y \\
\theta \\
M \\
Q
\end{array}\right]_{i}^{L}=\left[\begin{array}{cccc}
1 & l_{i} & \frac{l_{i}^{2}}{\left(2 E_{i} I_{i}\right)} & \frac{l_{i}^{3}}{\left(6 E_{i} I_{i}\right)} \\
0 & 1 & \frac{l_{i}}{\left(E_{i} I_{i}\right)} & \frac{l_{i}^{2}}{\left(2 E_{i} I_{i}\right)} \\
0 & 0 & 1 & l_{i} \\
0 & 0 & 0 & 1
\end{array}\right]\left[\begin{array}{c}
y \\
\theta \\
M \\
Q
\end{array}\right]_{i-1}^{R}
$$

which also can be abbreviated as

$$
Z_{i}^{L}=H_{i}^{F} Z_{i-1}^{R} \text {, }
$$

where $H_{i}^{F}$ represents the field transfer matrix.

When the crack is located at the section of the $i$ th centralized quality $m_{i}$ (Figure 7 ), the angle of rotation around $m_{i}$ is different, which can be written as

$$
\theta_{i}^{R}=\theta_{i}^{L}+c M,
$$

where $c$ is the additional flexibility [26] and $M$ is the bending moment of the crack section.

The equilibrium condition of the $i$ th centralized quality $m_{i}$ can be written as follows:

$$
\begin{aligned}
y_{i}^{R} & =y_{i}^{L} \\
\theta_{i}^{R} & =\theta_{i}^{L}+c M_{i}^{L} \\
M_{i}^{R} & =M_{i}^{L} \\
Q_{i}^{R} & =Q_{i}^{L}+m_{i} \omega^{2} y_{i},
\end{aligned}
$$

where $\omega$ is the natural frequency of the blade.

Thus the transfer matrix between the right side of $m_{i}$ and the left side of $m_{i}$ can be given by

$$
\left[\begin{array}{c}
y \\
\theta \\
M \\
Q
\end{array}\right]_{i}^{R}=\left[\begin{array}{cccc}
1 & 0 & 0 & 0 \\
0 & 1 & c & 0 \\
0 & 0 & 1 & 0 \\
m_{i} \omega^{2} & 0 & 0 & 1
\end{array}\right]\left[\begin{array}{c}
y \\
\theta \\
M \\
Q
\end{array}\right]_{i}^{L},
$$

abbreviated as

$$
Z_{i}^{R}=H_{i}^{P} Z_{i}^{L}
$$

where $H_{i}^{P}$ represents the point transfer matrix. 


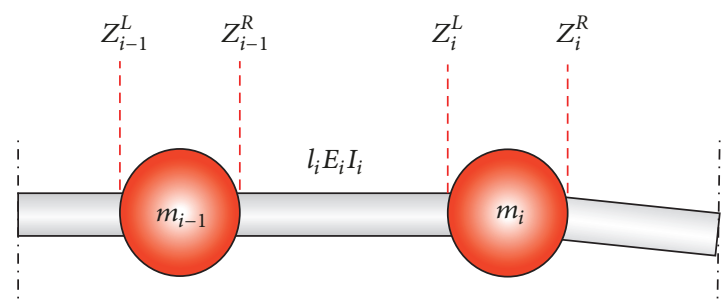

(a)

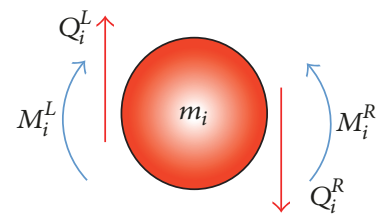

(b)

Figure 7: (a) Mathematical model of the crack blade and (b) stress analysis of the centralized quality $m_{i}$.

Then the whole $i$ th unit transfer matrix can be calculated as follows:

$$
H_{i}=\left[\begin{array}{cccc}
1 & l_{i} & \frac{l_{i}^{2}}{\left(2 E_{i} I_{i}\right)} & \frac{l_{i}^{3}}{\left(6 E_{i} I_{i}\right)} \\
0 & 1 & c+\frac{l_{i}}{\left(E_{i} I_{i}\right)} & c l_{i}+\frac{l_{i}^{2}}{\left(2 E_{i} I_{i}\right)} \\
0 & 0 & 1 & l_{i} \\
m_{i} \omega^{2} & m_{i} \omega^{2} l_{i} & \frac{l_{i}}{\left(E_{i} I_{i}\right)} & 1+\frac{m_{i} \omega^{2} l_{i}^{3}}{\left(6 E_{i} I_{i}\right)}
\end{array}\right] .
$$

And the transfer matrix of mathematical model (Figure 8) of the whole crack blade can be defined as

$$
Z_{n}^{R}=H Z_{0} \text {, }
$$

where $H=H_{n} H_{n-1} \cdots H_{i} \cdots H_{1}$.

Then the relation between the blade tip and the blade root can be expressed as follows:

$$
\left[\begin{array}{c}
y \\
\theta \\
M \\
Q
\end{array}\right]_{n}^{R}=\left[\begin{array}{llll}
h_{11} & h_{12} & h_{13} & h_{14} \\
h_{21} & h_{22} & h_{23} & h_{24} \\
h_{31} & h_{32} & h_{33} & h_{34} \\
h_{41} & h_{42} & h_{43} & h_{44}
\end{array}\right]\left[\begin{array}{c}
y \\
\theta \\
M \\
Q
\end{array}\right]_{0}
$$

According to the blade boundary conditions, where $y_{0}=$ $\theta_{0}=0, M_{n}^{R}=Q_{n}^{R}=0$, (14) can be readily simplified as

$$
\begin{aligned}
& h_{33} M_{0}+h_{34} Q_{0}=M_{n}^{R} \\
& h_{43} M_{0}+h_{44} Q_{0}=Q_{n}^{R} .
\end{aligned}
$$

Because $M_{0}, Q_{0}$ could not be zero at the same time and because of the condition of the homogeneous linear equations having nonzero solutions, (15) can be calculated as

$$
\left|\begin{array}{ll}
h_{33} & h_{34} \\
h_{43} & h_{44}
\end{array}\right|=0
$$

which can get the value of $\omega$.

Through the above analysis, it is obvious to find out that when a single crack exists in a blade structure, the natural frequency of the blade is bound to change. Consequently, the natural frequency can be regarded as a fault feature to detect the crack damage in fan blades.
TABLE 1: Natural frequencies of the plate blade in $\mathrm{Hz}$.

\begin{tabular}{lccc}
\hline & $\begin{array}{c}\text { Theoretical } \\
\text { value }\end{array}$ & $\begin{array}{c}\text { Simulation } \\
\text { value }\end{array}$ & Relative error \\
\hline Mode 1 & 48.629 & 49.556 & $1.9 \%$ \\
Mode 2 & 304.756 & 308.240 & $1.1 \%$ \\
Mode 3 & 853.324 & 857.320 & $0.4 \%$ \\
\hline
\end{tabular}

\section{Results and Discussions}

3.1. Results. The first three natural frequencies of the theoretical value and the simulation value are shown in Table 1.

There is a relative error between the simulation value and the theoretical value, and the main reason of this issue is the stress caused by high-speed rotation. Every infinitesimal quality segment in the blade suffered a centrifugal force which could prompt the blade back to the equilibrium position while the blade vibrates in the rotation or axial plane. The working of this kind of centrifugal force corresponds to that of the elastic restoring force of the blade, which leads to the natural frequency of each order of blade being higher than that while not working.

It is assumed that the natural frequency of each mode of the intact blade is represented by $\omega_{n}(n=1,2,3)$ and the natural frequencies of all the damaged blade conditions are represented by $\omega_{c}$. The simulation data were tabulated in the form of frequency ratio $\left(\omega_{c} / \omega\right)$ versus the crack size $\alpha$ for each crack location $\beta$. Tables $2-4$ show the variation of the frequency as a function of the crack size and crack location for plate blade.

3.2. Changes in Natural Frequencies. Figure 9 shows the plots curve-fitted from the simulation data of the variations of the first three frequency ratios as a function of crack location ratios $(\beta / l)$ for three different crack size ratios $(\alpha / h)$ considered for each set of boundary conditions. Figure 10 illustrates the variations of the first three natural frequencies as a function of crack size ratios $(\alpha / h)$ for all of the crack location ratios $(\beta / l)$ considered for each set of boundary conditions (eight locations were considered for each set of boundary conditions).

From the simulation results and plots, the following observations are made for all the cases considered:

(1) For all the cases considered, crack reduces the natural frequency of the blade. 


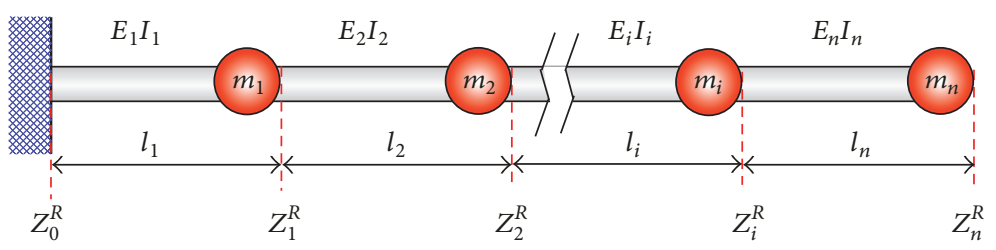

FIGURE 8: Mathematical model of the whole crack blade.
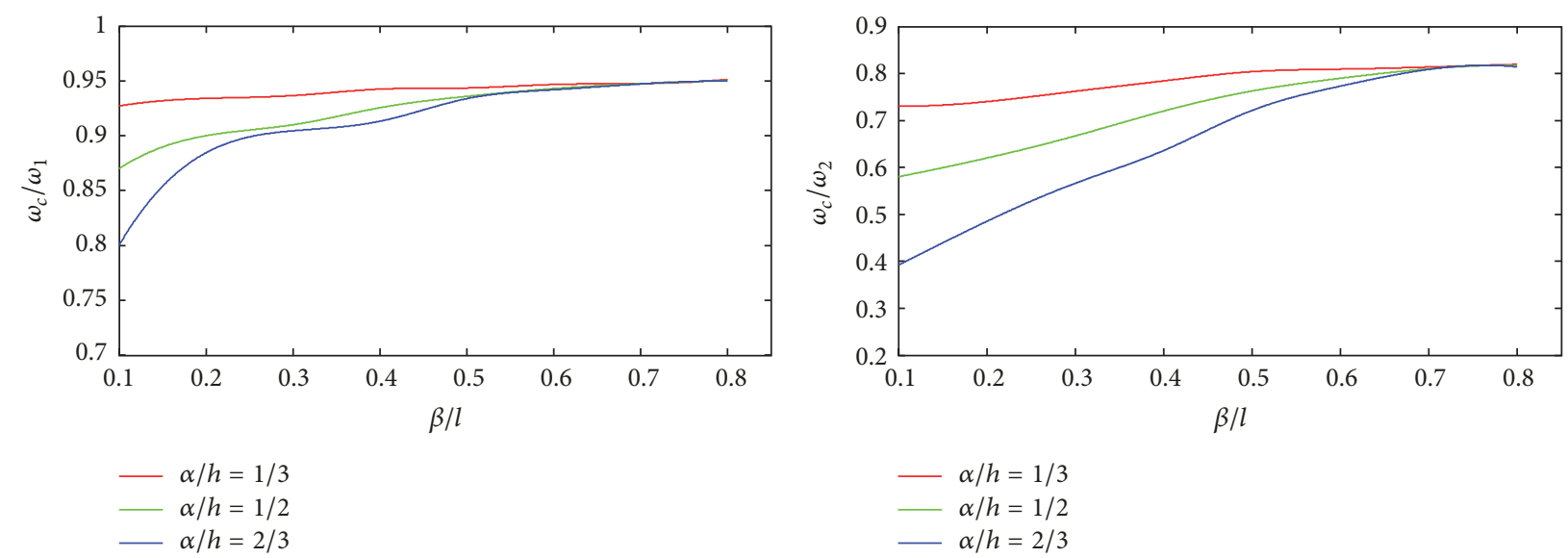

(a)

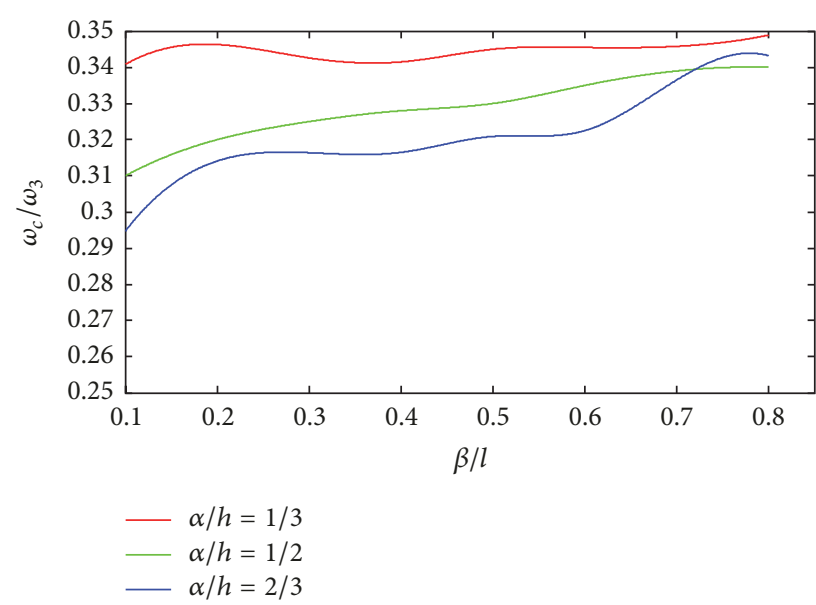

(c)

Figure 9: Normalized natural frequencies (of various modes) in terms of crack location ratios $\beta / l$ for various crack size ratios $\alpha / h$ : (a) mode 1; (b) mode 2; (c) mode 3.

(2) The fundamental natural frequency is generally affected the least while the third natural frequency of blade changes rapidly for all the cases.

(3) For each mode, as the crack size increases, the natural frequency of blade decreases distinctly while the crack location is identical.

(4) For each mode, the natural frequency of blade decreases significantly as the crack location moves towards the blade root while the crack size is identical.

(5) For a few of the cases considered, such as when the crack size ratio $\alpha / h$ is $1 / 3$ or the crack location ratio $\beta / l$ is $8 / 9$, the frequencies remain nearly unchanged (see Figures 9 and 10) until a certain value of crack size ratio or crack location ratio is attained, after which the frequencies decrease rapidly.

From the above observations, it could be stated that the existence of crack will reduce the natural frequency of the whole blade structure. The natural frequencies changed monotonically for being a function of either the crack sizes or the crack locations. The natural frequency is a function of not only crack size or crack location, but also the mode number. In general, the higher the number of modes being used, the better the accuracy and dependability of predicted results will be. 
TABLE 2: Fundamental natural frequency ratio $\left(\omega_{c} / \omega_{1}\right)$ as a function of crack location and size for the blade.

\begin{tabular}{ccccccccc}
\hline$\alpha / h$ & $\beta / l=1 / 9$ & $\beta / l=2 / 9$ & $\beta / l=3 / 9$ & $\beta / l=4 / 9$ & $\beta / l=5 / 9$ & $\beta / l=6 / 9$ & $\beta / l=7 / 9$ & $\beta / l=8 / 9$ \\
\hline $1 / 3$ & 0.9271 & 0.9340 & 0.9366 & 0.9425 & 0.9435 & 0.9467 & 0.9476 & 0.9515 \\
$1 / 2$ & 0.8712 & 0.9024 & 0.9121 & 0.9255 & 0.9359 & 0.9430 & 0.9474 & 0.9505 \\
$2 / 3$ & 0.8002 & 0.8845 & 0.9045 & 0.9132 & 0.9338 & 0.9149 & 0.9472 & 0.9498 \\
\hline
\end{tabular}

TABLE 3: Second natural frequency ratio $\left(\omega_{c} / \omega_{2}\right)$ as a function of crack location and crack size for the blade.

\begin{tabular}{ccccccccc}
\hline$\alpha / h$ & $\beta / l=1 / 9$ & $\beta / l=2 / 9$ & $\beta / l=3 / 9$ & $\beta / l=4 / 9$ & $\beta / l=5 / 9$ & $\beta / l=6 / 9$ & $\beta / l=7 / 9$ & $\beta / l=8 / 9$ \\
\hline $1 / 3$ & 0.7305 & 0.7401 & 0.7621 & 0.7842 & 0.8039 & 0.8093 & 0.8138 & 0.8195 \\
$1 / 2$ & 0.5801 & 0.6220 & 0.6671 & 0.7223 & 0.7627 & 0.7899 & 0.8124 & 0.8173 \\
$2 / 3$ & 0.3918 & 0.4851 & 0.5662 & 0.6358 & 0.7214 & 0.7731 & 0.8088 & 0.8142 \\
\hline
\end{tabular}

TABLE 4: Third natural frequency ratio $\left(\omega_{c} / \omega_{3}\right)$ as a function of crack location and crack size for the blade.

\begin{tabular}{ccccccccc}
\hline$\alpha / h$ & $\beta / l=1 / 9$ & $\beta / l=2 / 9$ & $\beta / l=3 / 9$ & $\beta / l=4 / 9$ & $\beta / l=5 / 9$ & $\beta / l=6 / 9$ & $\beta / l=7 / 9$ & $\beta / l=8 / 9$ \\
\hline $1 / 3$ & 0.3408 & 0.3463 & 0.3426 & 0.3415 & 0.3450 & 0.3455 & 0.3458 \\
$1 / 2$ & 0.3123 & 0.3221 & 0.3254 & 0.3287 & 0.3310 & 0.3357 & 0.3391 \\
$2 / 3$ & 0.2947 & 0.3141 & 0.3164 & 0.3165 & 0.3209 & 0.3225 & 0.3365 & 0.3454 \\
\hline
\end{tabular}

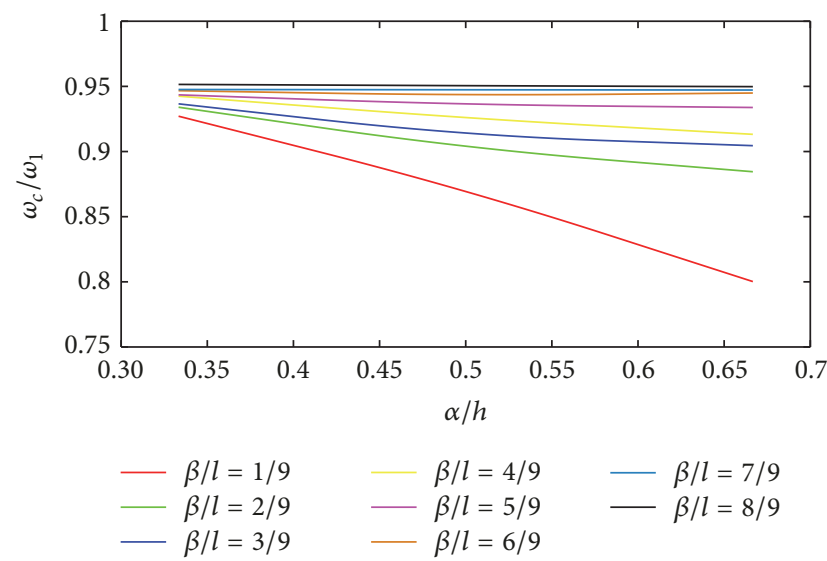

(a)

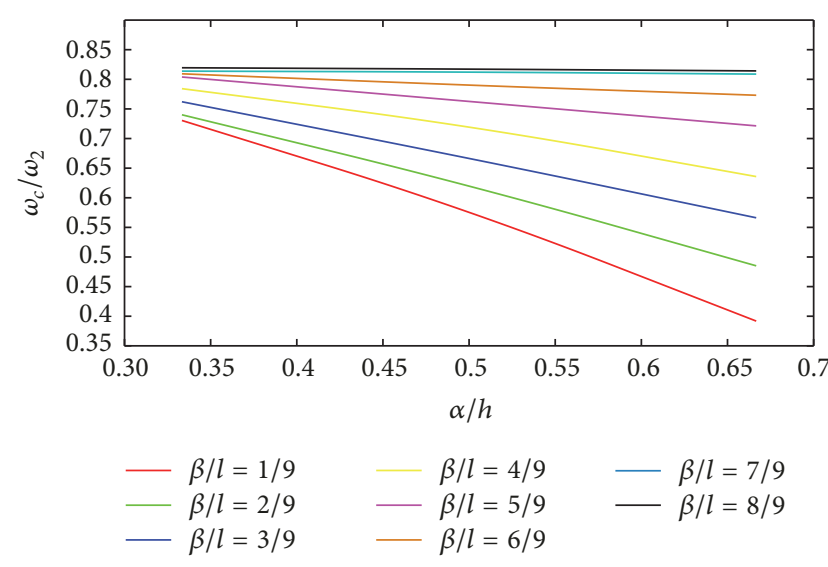

(b)

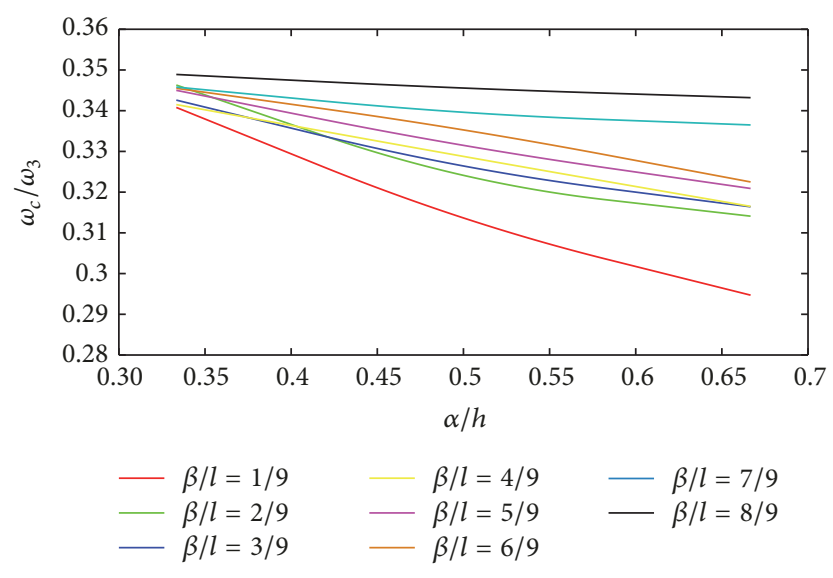

(c)

FIGURE 10: Normalized natural frequencies (of various modes) in terms of crack size ratios $\alpha / h$ for various crack locations $\beta / l$ : (a) mode 1 ; (b) mode 2; (c) mode 3. 


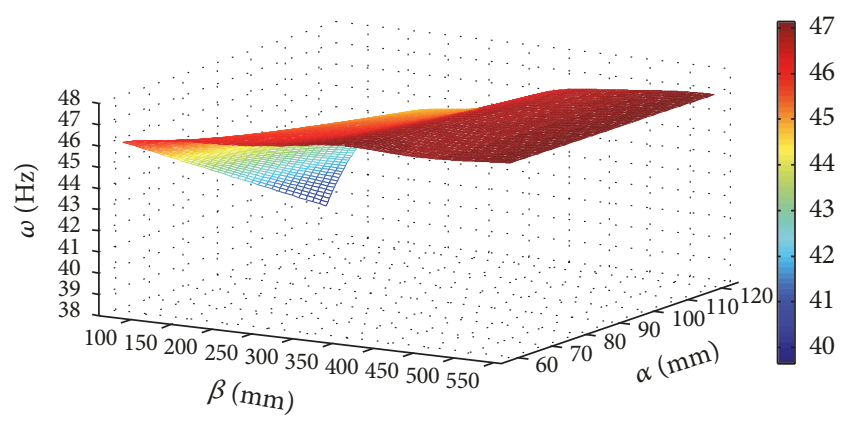

(a) Mode 1

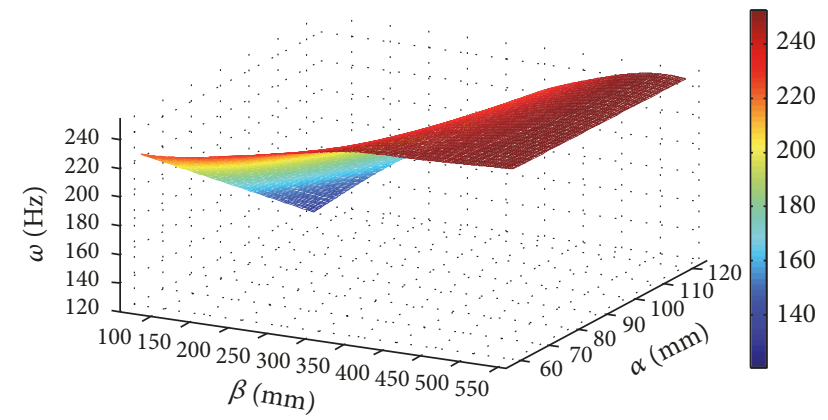

(b) Mode 2

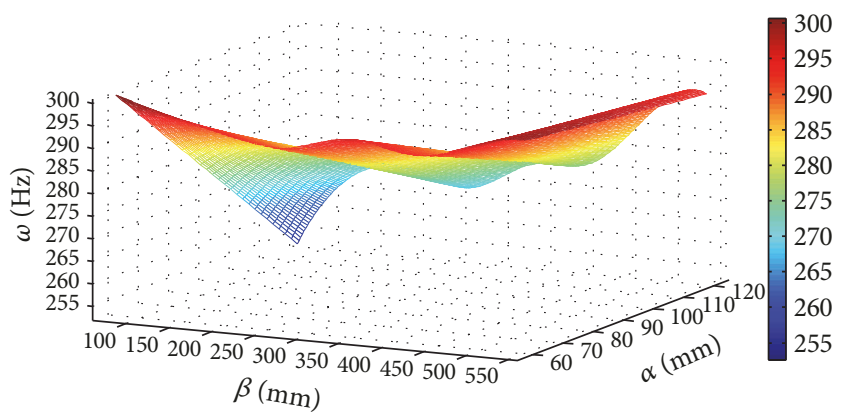

(c) Mode 3

FIGURE 11: Three-dimensional plots of frequency versus crack location and crack size for the plate blade.

\subsection{Crack Identification Technique Using Changes in Natural} Frequencies. Based on the simulated frequency changes, a method of identifying a crack location and crack size is presented in this section.

As stated earlier, both the crack location and the crack size influence the change in the natural frequencies of a cracked blade. It can be clearly concluded from the three-dimensional plots of the first three natural frequencies $(\omega)$ of plate blade (Figure 11) that a particular frequency could correspond to different crack locations and crack sizes; that is, the natural frequency is a function of crack size and crack location.

To identify the state of the crack in plate blade, an essential step should be taken to achieve a sufficient number of natural frequencies of the blade and then build the fault database. The number of cracks determines the order of natural frequency required for diagnosis. For a single crack, the first three natural frequencies are sufficient to diagnose the location and size.

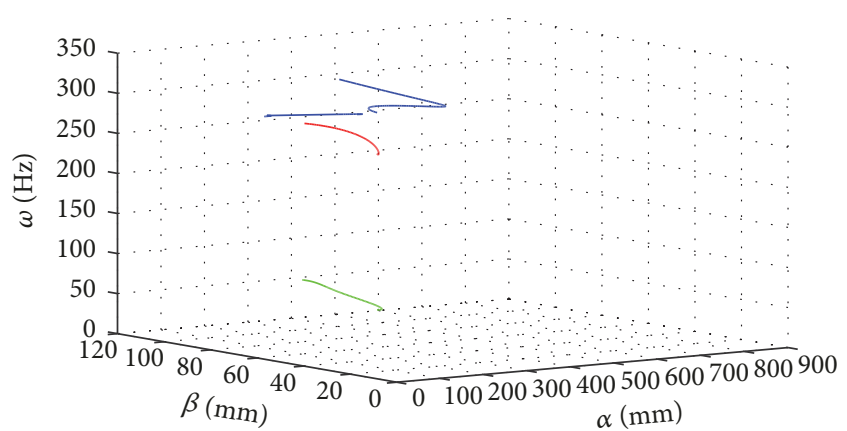

$$
\begin{aligned}
-\omega & =46.709 \mathrm{~Hz} \\
-\omega & =241.71 \mathrm{~Hz} \\
-\omega & =292.81 \mathrm{~Hz}
\end{aligned}
$$

FIGURE 12: Three-dimensional plots of contour lines for the plate blade.

For a blade with a single crack, the diagnostic process is as follows:

(1) Measuring the first three natural frequencies of the plate blade

(2) Using a horizontal plane at each one of the three natural frequencies to cut the fault database and then plotting the contour of the frequencies under different modalities in the same axis system

(3) Through positioning the intersection of the different contours of the natural frequencies, readily determining the location and size of the crack.

Because any crack frequency can be represented by a governing equation which is dependent on crack size $\alpha$, crack location $\beta$, and mode number, the intersection becomes unique. Therefore a minimum of three curves is required to identify the two unknown parameters of crack location and crack size.

Diagnostic procedure, for example, is as follows.

From Tables 2-4, it is observed that, for a crack size ratio $(\alpha / h)$ of $1 / 3$ located at a distance of $4 / 9 l$ away from the blade root, the frequencies are $46.709 \mathrm{~Hz}$ for the first mode, $241.71 \mathrm{~Hz}$ for the second mode, and $292.81 \mathrm{~Hz}$ for the third mode. Using a horizontal plane to cut the fault database at each one of the three frequencies, the contour lines with the values of $46.709 \mathrm{~Hz}, 241.71 \mathrm{~Hz}$, and $292.81 \mathrm{~Hz}$ were retrieved from the first three modes (see Figure 12) and plotted on the same axes as shown in Figure 13. From the figure, it could be observed that the three contour lines gave just one common point of intersection, which indicates the crack location and the crack size.

If the crack location coincides with a vibration node, the contour line tends to disappear, and no intersections can be obtained. In such a case, higher natural frequencies may have to be obtained to predict the location and the size of the crack. The experimental verification of this fault diagnostic technique may be investigated in the future by the authors. 
TABLE 5: Experimental results of the blade.

\begin{tabular}{lcccccccccc}
\hline $\begin{array}{l}\text { Crack } \\
\text { location } \beta\end{array}$ & $\begin{array}{c}\text { Crack } \\
\text { depth } \alpha\end{array}$ & \multicolumn{3}{c}{ Experimental result $\omega_{i}(\mathrm{~Hz})$} & \multicolumn{3}{c}{ Theoretical result $\omega_{i}(\mathrm{~Hz})$} & \multicolumn{3}{c}{ Relative error $(\%)$} \\
\hline 0 & 0 & 4.511 & 28.300 & 78.891 & 4.870 & 30.410 & 85.442 & 0.21 & 2.23 & 2.56 \\
60 & 60 & 4.592 & 28.132 & 79.213 & 4.538 & 29.803 & 80.502 & 0.59 & 5.04 & 2.00 \\
190 & 60 & 4.773 & 28.074 & 78.855 & 4.739 & 29.527 & 81.902 & 3.10 & 4.72 & 3.28 \\
310 & 60 & 4.824 & 29.244 & 79.946 & 4.842 & 29.040 & 80.488 & 1.43 & 3.33 & 2.03 \\
440 & 60 & 3.769 & 27.016 & 69.262 & 4.869 & 30.293 & 82.781 & 0.92 & 3.46 & 3.42 \\
60 & 90 & 4.326 & 27.996 & 77.232 & 4.180 & 29.342 & 71.981 & 9.83 & 7.93 & 3.40 \\
190 & 90 & 4.685 & 27.847 & 71.048 & 4.568 & 28.621 & 77.839 & 5.30 & 2.18 & 0.78 \\
310 & 90 & 4.725 & 29.903 & 73.001 & 4.780 & 27.380 & 71.218 & 1.99 & 1.71 & 0.24 \\
440 & 90 & 4.511 & 28.300 & 78.891 & 4.792 & 29.944 & 72.963 & 1.40 & 0.14 & 0.05 \\
125 & 80 & 4.260 & 29.672 & 78.068 & 4.477 & 29.508 & 79.332 & 4.85 & 0.56 & 1.59 \\
\hline
\end{tabular}

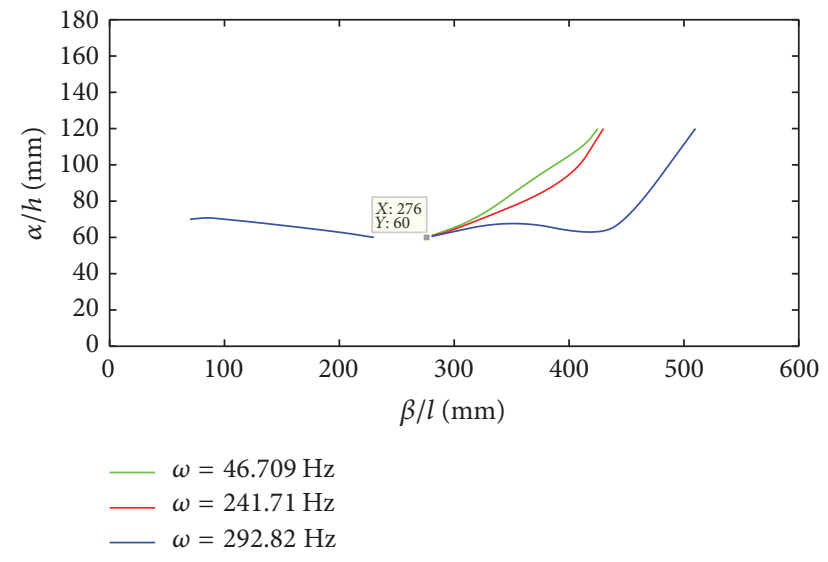

FIGURE 13: Crack identification technique using frequency contours of first three modes in a plate blade.

\section{Experimental Validation}

To verify the feasibility of the theoretical method, natural frequencies of the blades were obtained through modal experiment. This chapter takes straight blade as the research object and the blade crack is a transverse opening crack. The blades are $500 \mathrm{~mm}$ long, $180 \mathrm{~mm}$ wide, and $1.5 \mathrm{~mm}$ thick and their density and modulus of elasticity are $7930 \mathrm{~kg} / \mathrm{m}^{2}$ and $190 \mathrm{Gpa}$, respectively. The experimental system mainly consists of a blade, a force hammer, acceleration sensors, a data acquisition and analysis system INV3020C, and the DASP software (see Figure 14). The mode shapes obtained by DASP are shown in Figure 15.

The first three order natural frequencies of the blades obtained by the modal test and theoretical results are shown in Table 5; it shows small errors between the theoretical computation results and the experimental results. It is proved that the theoretical calculation model is accurate and effective. According to the natural frequencies, the database of the blade fault samples is constructed (see Figure 16).

The validity of the method proposed in the last chapter is verified according to the database. The natural frequencies of the blade with a crack at $\beta=125 \mathrm{~mm}$ and $\alpha=80 \mathrm{~mm}$

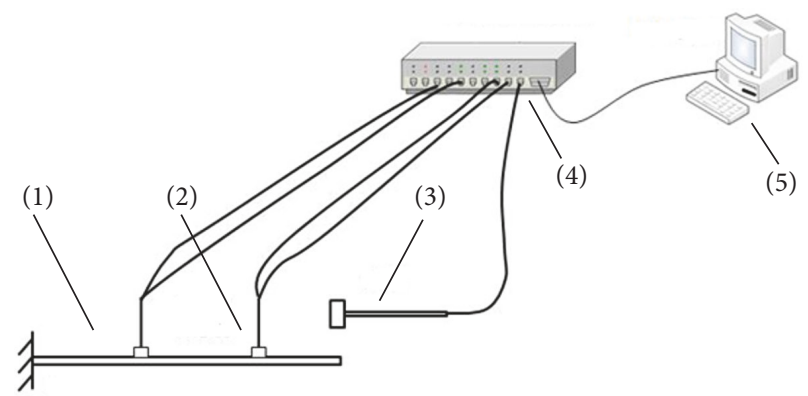

(a) The schematic diagram of the experimental system: (1) blade; (2) acceleration sensor; (3) force hammer; (4) INV3020C; (5) DASP

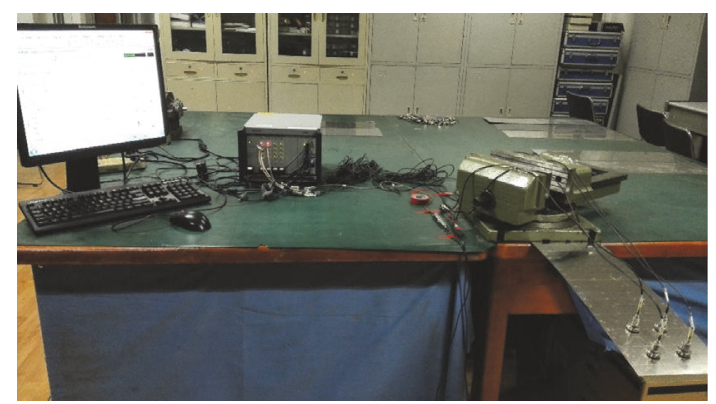

(b) Arrangement diagram of the experimental system

Figure 14

have three intersection curves with each order fault sample database. The three contours are plotted in the same coordinate system, as illustrated in Figure 17. The coordinates of the points of intersection are the location and size of the crack.

Therefore, the mathematical model presented in this paper can calculate the natural frequency of the cracked blade accurately, and the method proposed in this paper can determine the location and size of the crack accurately, so as to diagnose the crack failure effectively.

\section{Conclusions}

Theoretical analysis of the effects on natural frequency of a single crack in fan blade has been presented in this paper in detail. The vibration characteristics of blade are shown to 


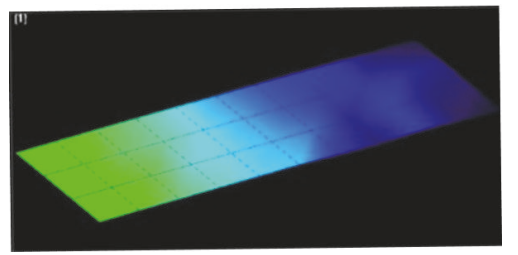

(a) Mode 1

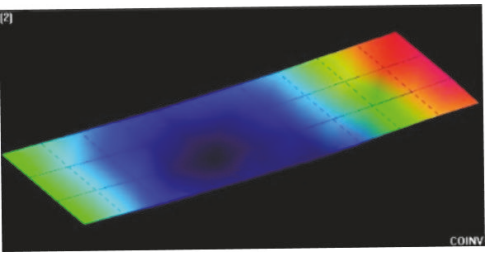

(b) Mode 2

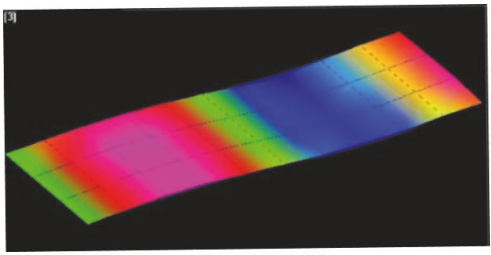

(c) Mode 3

FIGURE 15: The first three order mode shapes obtained by DASP.

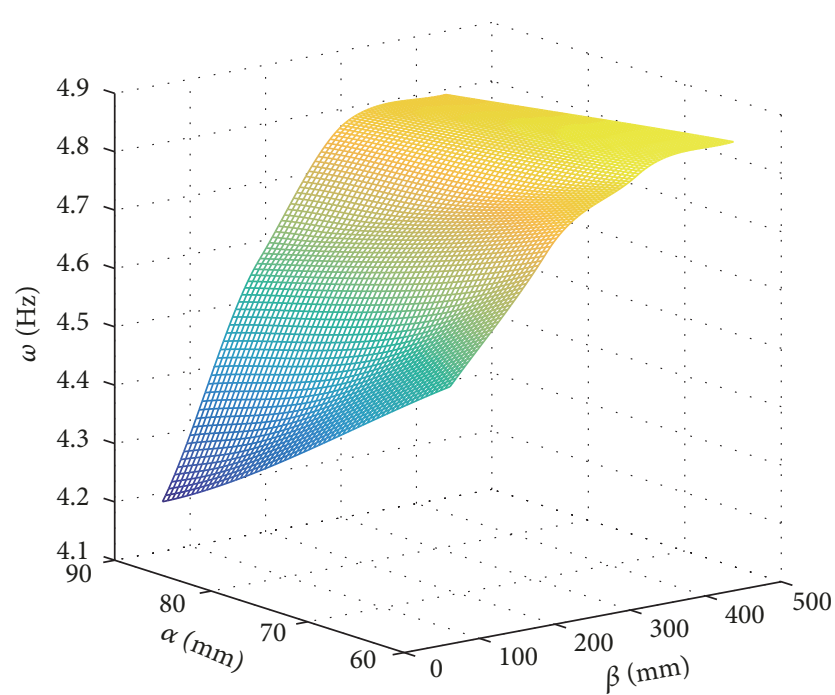

(a) Mode 1

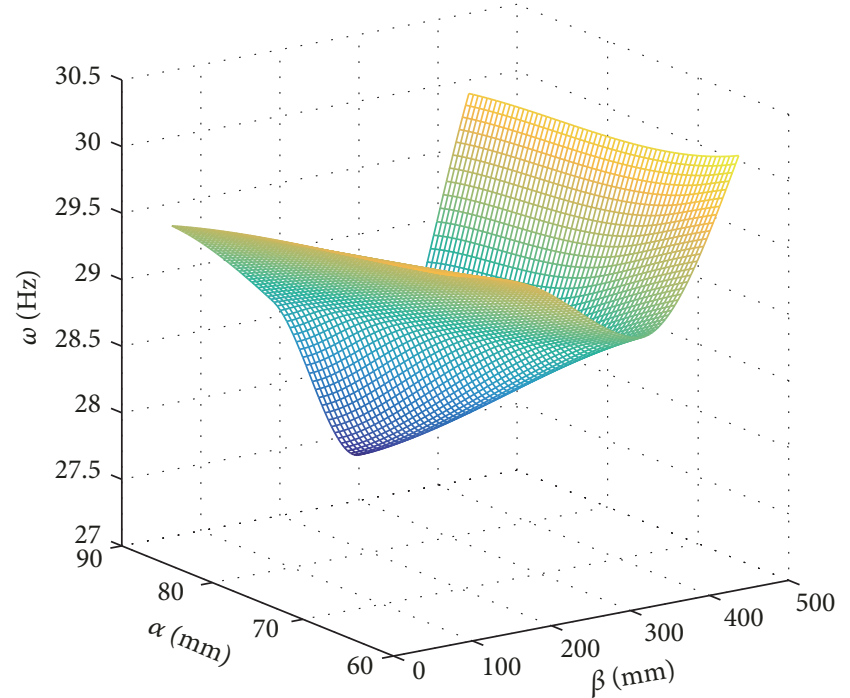

(b) Mode 2

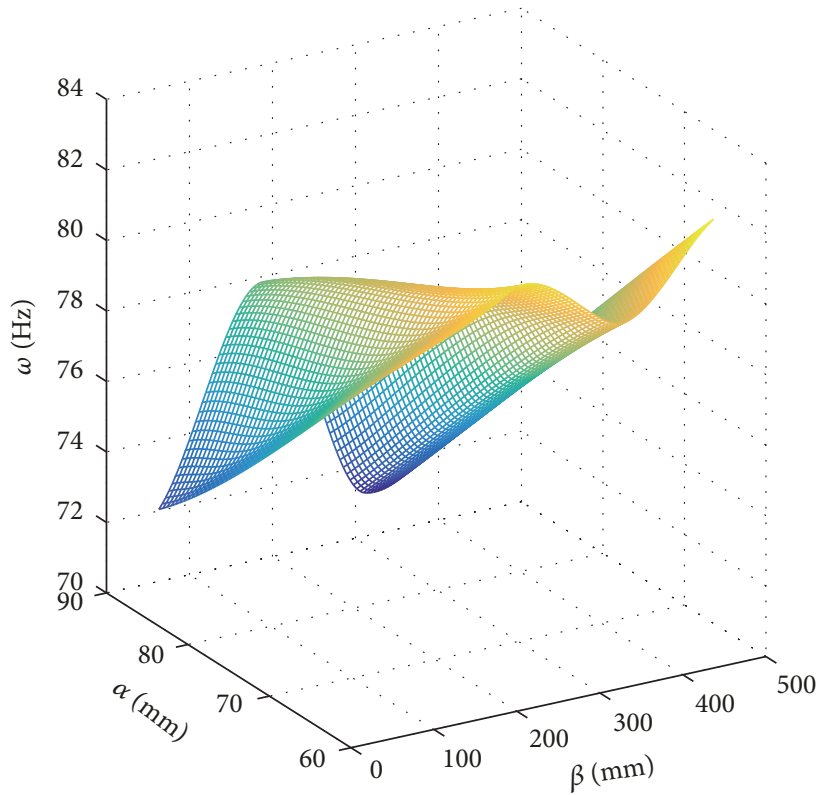

(c) Mode 3

FigURE 16: Three-dimensional surfaces of frequency versus crack location and crack depth for a single crack blade. 


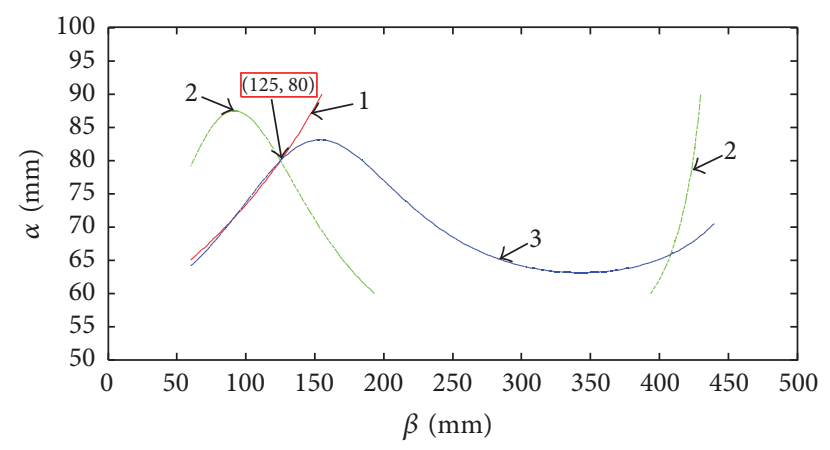

FIGURE 17: Crack identification technique by using frequency contours: (1) mode 1; (2) mode 2; (3) mode 3.

be very sensitive to the crack location, crack size, and mode number. An effective method of predicting location and size of the crack based on changes in natural frequencies of plate blade is also proposed and discussed. Numerical simulations for damage detection of a single crack blade using CFD and FEM method are investigated to evaluate the proposed method. The fault diagnosis technique presented in this paper proved to be effective and useful in the simulation condition. As the frequency can be measured precisely using accelerator sensors, the proposed method provides a useful tool for damage detection and diagnosis of fan blade. Furthermore, the feasibility of this method is verified through experimental data.

\section{Conflicts of Interest}

The authors declare that there are no conflicts of interest regarding the publication of this paper.

\section{References}

[1] S. K. Bhaumik, T. A. Bhaskaran, R. Rangaraju, M. A. Venkataswamy, M. A. Parameswara, and R. V. Krishnan, "Failure of turbine rotor blisk of an aircraft engine," Engineering Failure Analysis, vol. 9, no. 3, pp. 287-301, 2002.

[2] H. Kim, "Crack evaluation of the fourth stage blade in a lowpressure steam turbine," Engineering Failure Analysis, vol. 18, no. 3, pp. 907-913, 2011.

[3] S. Wang, Y. Zi, Z. Wan, B. Li, and Z. He, "Effects of multiple cracks on the forced response of centrifugal impellers," Mechanical Systems and Signal Processing, vol. 60, pp. 326-343, 2015.

[4] A. J. Oberholster and P. S. Heyns, "On-line fan blade damage detection using neural networks," Mechanical Systems and Signal Processing, vol. 20, no. 1, pp. 78-93, 2006.

[5] S. W. Liu, J. H. Huang, J. C. Sung, and C. C. Lee, "Detection of cracks using neural networks and computational mechanics," Computer Methods Applied Mechanics and Engineering, vol. 191, no. 25-26, pp. 2831-2845, 2002.

[6] C.-B. Yun and E. Y. Bahng, "Substructural identification using neural networks," Computers \& Structures, vol. 77, no. 1, pp. 41$52,2000$.

[7] F. S. Buezas, M. B. Rosales, and C. P. Filipich, "Damage detection with genetic algorithms taking into account a crack contact model," Engineering Fracture Mechanics, vol. 78, no. 4, pp. 695712, 2011.

[8] H. Liu, K. Xin, and Q. Qi, "Study of Structural Damage Detection with Multi-objective Function Genetic Algorithms," Procedia Engineering, vol. 12, pp. 80-86, 2011.

[9] M. Vakil-Baghmisheh, M. Peimani, M. H. Sadeghi, and M. M. Ettefagh, "Crack detection in beam-like structures using genetic algorithms," Applied Soft Computing, vol. 8, no. 2, pp. 1150-1160, 2008.

[10] M. Ananda Rao, J. Srinivas, and B. S. N. Murthy, "Damage detection in vibrating bodies using genetic algorithms," Computers \& Structures, vol. 82, no. 11-12, pp. 963-968, 2004.

[11] M. Mehrjoo, N. Khaji, and M. Ghafory-Ashtiany, "Application of genetic algorithm in crack detection of beam-like structures using a new cracked Euler-Bernoulli beam element," Applied Soft Computing, vol. 13, no. 2, pp. 867-880, 2013.

[12] V. T. Tran, B.-S. Yang, M.-S. Oh, and A. C. C. Tan, "Fault diagnosis of induction motor based on decision trees and adaptive neuro-fuzzy inference," Expert Systems with Applications, vol. 36, no. 2, pp. 1840-1849, 2009.

[13] Y. Lei, Z. He, Y. Zi, and Q. Hu, "Fault diagnosis of rotating machinery based on multiple ANFIS combination with GAs," Mechanical Systems and Signal Processing, vol. 21, no. 5, pp. 2280-2294, 2007.

[14] P. M. Pawar and R. Ganguli, "Genetic fuzzy system for online structural health monitoring of composite helicopter rotor blades," Mechanical Systems and Signal Processing, vol. 21, no. 5, pp. 2212-2236, 2007.

[15] R. A. Saeed, A. N. Galybin, and V. Popov, "3D fluid-structure modelling and vibration analysis for fault diagnosis of Francis turbine using multiple ANN and multiple ANFIS," Mechanical Systems and Signal Processing, vol. 34, no. 1-2, pp. 259-276, 2013.

[16] A. Maghsoodi, A. Ghadami, and H. R. Mirdamadi, "Multiplecrack damage detection in multi-step beams by a novel local flexibility-based damage index," Journal of Sound and Vibration, vol. 332, no. 2, pp. 294-305, 2013.

[17] A. K. Pandey, M. Biswas, and M. M. Samman, "Damage detection from changes in curvature mode shapes," Journal of Sound and Vibration, vol. 145, no. 2, pp. 321-332, 1991.

[18] Y. Wang, M. Liang, and J. Xiang, "Damage detection method for wind turbine blades based on dynamics analysis and mode shape difference curvature information," Mechanical Systems and Signal Processing, vol. 48, no. 1-2, pp. 351-367, 2014.

[19] H. Nahvi and M. Jabbari, "Crack detection in beams using experimental modal data and finite element model," International Journal of Mechanical Sciences, vol. 47, no. 10, pp. 14771497, 2005.

[20] N. T. Khiem and L. K. Toan, "A novel method for crack detection in beam-like structures by measurements of natural frequencies," Journal of Sound and Vibration, vol. 333, no. 18, pp. 4084-4103, 2014.

[21] G. M. Owolabi, A. S. J. Swamidas, and R. Seshadri, "Crack detection in beams using changes in frequencies and amplitudes of frequency response functions," Journal of Sound and Vibration, vol. 265, no. 1, pp. 1-22, 2003.

[22] K. H. Barad, D. S. Sharma, and V. Vyas, "Crack detection in cantilever beam by frequency based method," Procedia Engineering, vol. 51, pp. 770-775, 2013.

[23] X. F. Yang, A. S. J. Swamidas, and R. Seshadri, "Crack identification in vibrating beams using the energy method," Journal of Sound and Vibration, vol. 244, no. 2, pp. 339-357, 2001. 
[24] E. Poursaeidi and M. Salavatian, "Fatigue crack growth simulation in a generator fan blade," Engineering Failure Analysis, vol. 16, no. 3, pp. 888-898, 2009.

[25] L. Witek, "Experimental crack propagation and failure analysis of the first stage compressor blade subjected to vibration," Engineering Failure Analysis, vol. 16, no. 7, pp. 2163-2170, 2009.

[26] W. M. Ostachowicz and M. Krawczuk, "Analysis of the effect of cracks on the natural frequencies of a cantilever beam," Journal of Sound and Vibration, vol. 150, no. 2, pp. 191-201, 1991. 


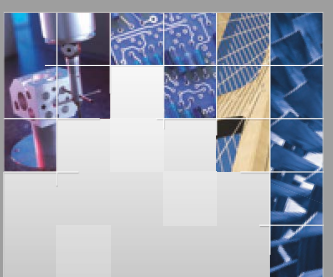

\section{Enfincering}
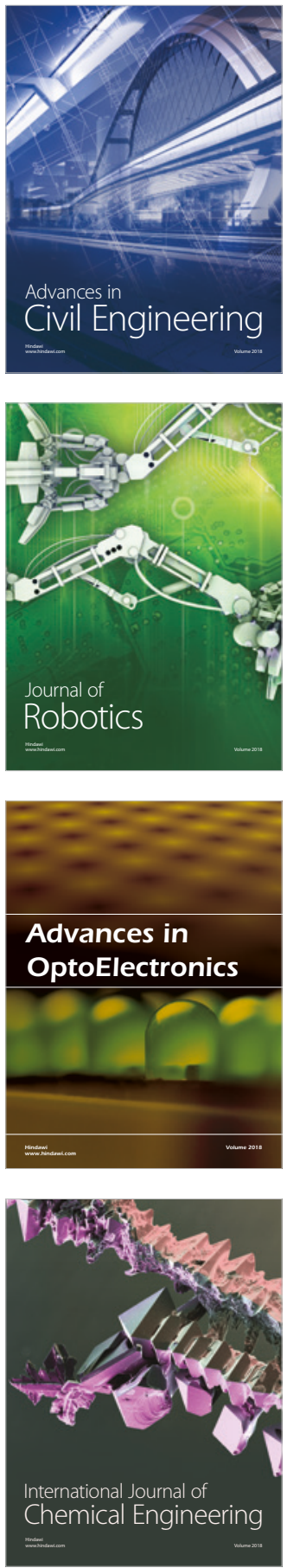

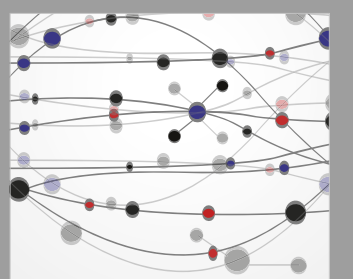

\section{Rotating \\ Machinery}

The Scientific World Journal

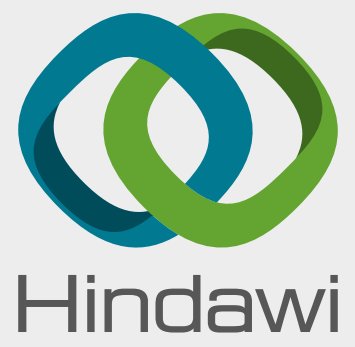

Submit your manuscripts at

www.hindawi.com
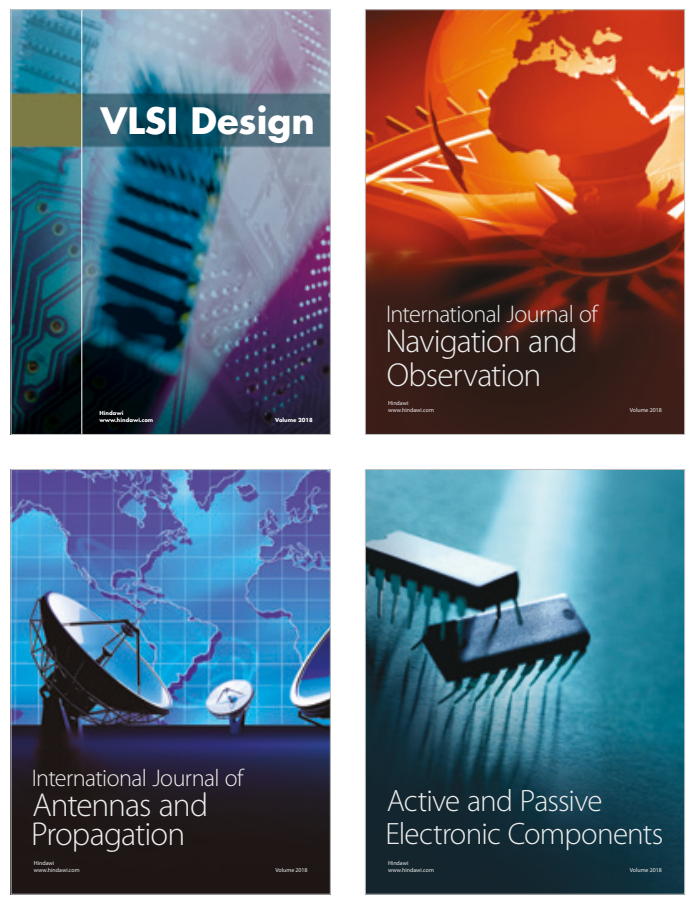
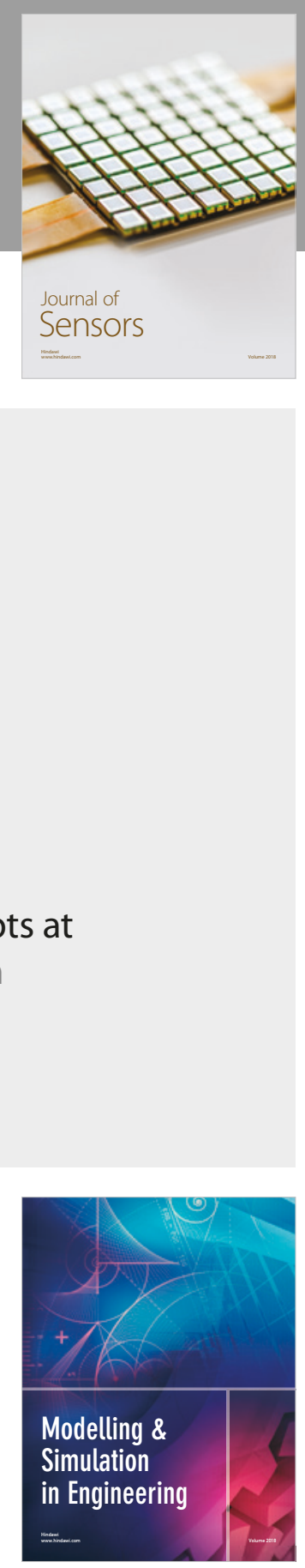

\section{Advances \\ Multimedia}
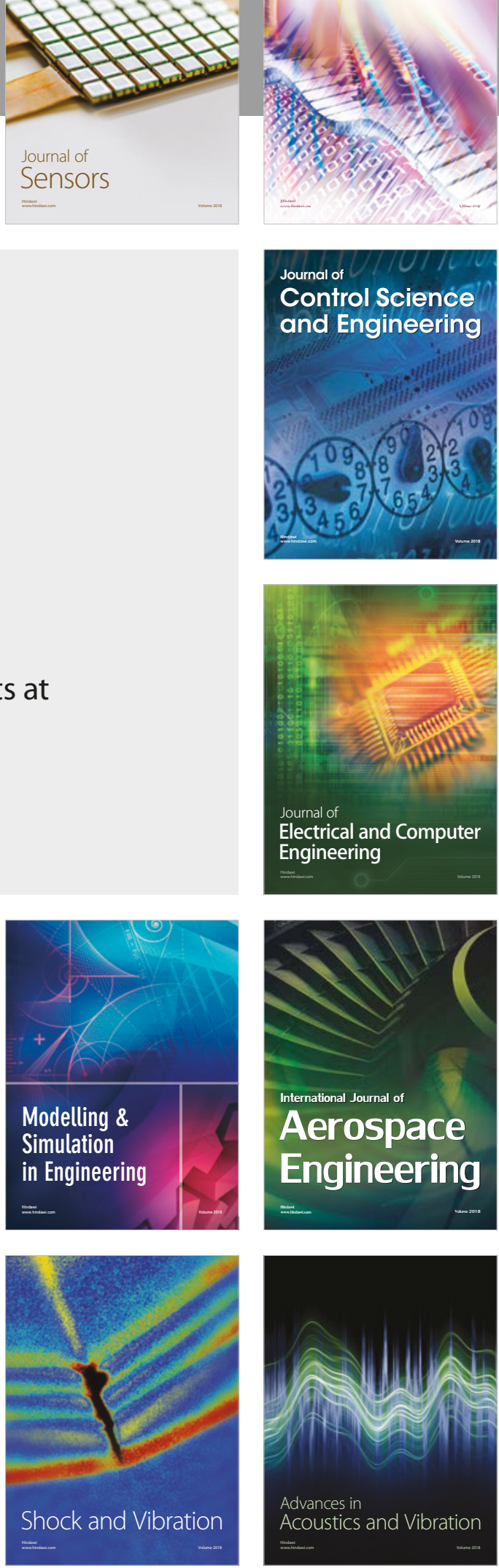